\title{
Somewhere between a Possibility and a Pipe Dream: District-level Leadership that

\author{
Promotes Family Inclusion and Engagement in Education
}

\author{
Catherine Hands \\ Brock University \\ Canada
}

\begin{abstract}
This paper looks at strengthening parent engagement in education, focusing on leadership strategies for reaching and supporting parents. The qualitative case study of a district's multiple approaches for enhancing parent engagement involved eight individual and focus group interviews, observations, and document analyses. The superintendent and principals shared leadership with school councils for developing initiatives. They collaborated with community organizations to provide parenting support, social services, and resources to enable participation. Despite some success, the leaders were challenged in establishing engagement programs widely across the district due to a managed, hierarchical, organizational structure and limited parent input on educational goals. The research contributes to a discussion of enhancing relations among families and schools to promote all students' academic achievement and wellbeing.
\end{abstract}

We always engage parents on our terms, and it hasn't worked. We are less effective as we have a more diverse group. We need to do things differently now. Students have changed, as has the parent body. They're not less engaged; the school is less accessible to them.

- Jasmeena Vaya ${ }^{1}$, first-year principal, District I (personal communication, June

A number of educators and their school districts in countries such as the United States and Canada view collaboration is an avenue through which students' needs may be met and achievement promoted. Home-school collaborative activities have a shared focus on students to assist all children to succeed academically and enhance positive selfesteem, independence, and life skills (Davies, 2002; Epstein, 1995, 2001; Henderson, Mapp, Johnson, \& Davies, 2007; Hoover-Dempsey, Bassler, \& Brissie, 1992).

Moreover, learning opportunities and plans for school change with contributions from all

ISSN 2325-6389 
stakeholders including parents are most likely to promote student achievement, reduce achievement gaps among students and engage families in education (Jeynes, 2005; Quezada, 2003; Pushor, 2007; Pushor \& Ruitenberg, 2005). Yet, as the quote at the beginning of this paper indicates, there is often a disconnect between educators' expectations for participation and parent engagement. Despite the interest in schoolcommunity engagement in education, collaboration is not widespread, especially in marginalized areas (Schutz, 2006); community members are involved in their schools peripherally if at all. "While an urban school is located in a community, it is not often of the community" (Keyes \& Gregg, 2001, p. 32).

Some scholars have noted the importance of district support in developing and sustaining parent engagement programs (see Epstein, Gallindo, Sheldon, \& Williams, 2007; Sanders, 2007). District leadership and assistance to schools facilitates school personnel's ability to plan collaborative activities with parents and communities (Epstein et al., 2007; Sanders, 2007). As a start, Epstein and colleagues recommended the appointment of one district leader to take on the role of expert in understanding family and community engagement in education and to take responsibility for developing and managing collaborative initiatives. District leadership may also include providing funding and material resources, as well as leading by example and demonstrating a commitment to school-family-community partnerships (Epstein et al., 2007; Sanders, 2007). With the value of district-level support for parent engagement highlighted in the literature, a closer examination of what district support looks like would be beneficial. This paper seeks to build on the existing research by examining how district-level actions operationalize parent engagement at the school level.

Recognizing the importance of district support for family engagement in education, the Canadian province of Ontario's Ministry of Education ${ }^{2}$ has established a Parent Engagement Office (PEO). The PEO is dedicated to developing and financially supporting parent engagement initiatives across the school districts in the province through research and policy-making (Ministry of Education, 2005). This paper is based on a larger research study evaluating eight different Ministry-funded strategies with the potential to strengthen partnerships between parents and schools and promote student learning. In examining the initiatives, a series of sub-questions were considered. They included: What successful strategies have these projects used to reach and support parents who face barriers to engagement? and What challenges have the projects encountered? In keeping with the call for district-level expertise on home-school collaboration and commitment to family engagement (Epstein et al., 2007), the focus for this paper is on one of the eight strategies in the larger study, as well as the role of one district's superintendent as a parent engagement initiative developer and facilitator of others' efforts to initiate and promote parent engagement. In a culturally and economically diverse district with articulated policies on parent engagement, the superintendent was responsible for parent engagement across the district and had developed a strategy with five different initiatives to promote family engagement in conjunction with other educators and parents. The study data from this district is used in this paper to examine the actions to put parent engagement into practice at schools characterized by diversity. 
In the section that follows, I offer definitions of parent engagement as well as descriptions of inclusion and the impact of diversity on parent engagement that situate the activities in the district and their potential for parent engagement in a culturally diverse community. I then discuss the type of leadership that facilitates engagement in education and the structures in the education system that mediate leadership.

\section{Parent Engagement}

Prior to discussing the initiatives, it is necessary to clarify what is meant by parent engagement. Some scholars make the distinction between parent involvement and parent engagement. For them, models of parent involvement place the focus on what parents can do to support goals and agendas of the school and the students that are established by educators in the schools and districts (Pushor, 2007). Here, decision-making is within the purview of school personnel not the families. Parent engagement, on the other hand, entails mutually determined educational agendas, shared power and authority over education with an understanding that parents, too, possess knowledge that contributes to teaching and learning (Pushor \& Ruitenberg, 2005). Increased parent engagement in their children's learning is most likely to enhance student achievement and reduce achievement gaps (Jeynes, 2005; Pushor, 2007; Quezada, 2003). As a result, student learning opportunities and school reform initiatives are developed with input from families as well as educators in the schools and districts (Harvard Family Research Project, 2002). The importance of distinctions among different levels of family participation in education and the origins of decision-making are acknowledged; however, the types of activities are not the only consideration. As Barton, Drake, Perez, St. Louis, and George (2004) note, much of the existing literature addresses the nature of parent engagement activities. For these scholars, the determination of engagement does not focus on the nature of the activities as much as how parents negotiate a space for participation in their children's education and their agency. With this in mind, this paper focuses on educational leadership and strategies for creating opportunities, or spaces, for diverse families to become engaged in schools.

\section{Issues of Inclusion}

When examining how families engage in educational issues, it is necessary to look at the contextual factors that help or hinder their participation. In their 2006 metaanalysis of 57 research articles on parent engagement, Leithwood and Jantzi found that 22 studies reported "social class, language, race and/or economic status were significant influences on the nature and quality of school-parent engagement" (p. 24). They determined that families from cultural minority groups, as well as those identified as low income, may experience challenges to participation in their children's education that other families within the school community may not.

Collaborative home-school activities that are shaped by dominant cultural practices in a community may limit the participation of families from cultural minorities if they are not familiar with the practices (Auerbach, 2011; Olivos, 2006). Parents' perceptions can also play a role in exclusion. In a study of low-income, AfricanAmerican mothers, the parents considered school personnel to be dismissive and 
disrespectful of them and their children (Cooper, 2009). In their study, Quiocho and Daoud (2005) found that Latino parents wanted to participate in their children's education, but some educators had misconceptions about the parents' roles and their ability to contribute to their children's education. Whether the parents were actually excluded is less important than their perceptions of exclusion. Parents' perceptions that they are being excluded or marginalized make future family engagement less likely to occur (Cooper, 2009).

As with issues related to cultural diversity, families' socioeconomic status (SES) might play a role in the amount and type of parent engagement at schools. For example, affluent parents have the power to shape and influence schools' curricula (Goldring, 1993; Oakes, Wells, Jones, \& Datnow, 1997). As well, upper middle-class families can assert their power to build the reputations of schools due to their influence in the local community (Metz, 1986). Conversely, parents of low SES usually do not have direct influence on their children's schooling (Metz, 1990). They may also find participating at schools in the ways expected by teachers to be difficult if they lack access to resources to enrich their children's education and available time to participate within the parameters of the schedule established by educators in the schools (Lareau, 1987). Additionally, educators may view families as being in need of resources rather than possessing any to contribute (cf. Parker \& Flessa, 2011). This deficit approach to family engagement makes it difficult to create opportunities for authentic home-school collaboration (Auerbach, 2011; Pushor, 2007).

Therefore, we see that families' characteristics influence school-family interactions (Lareau, 1987). Leithwood and Jantzi (2006) point out that diversity issues challenge educators in schools. This may be due to a discrepancy between the school personnel's lived experiences and those of the students and their families (Lareau, 1987; Metz, 1986, 1990). The personal and professional contexts experienced by families of low socio-economic status are not always well understood by school personnel: it is not always obvious why parents are not more involved in their children's schooling, and the expectations of some cultural groups for their children's education may not correspond with the training, experience, and expectations of the school personnel (Leithwood \& Jantzi, 2006). As a result, possibilities for family-school collaboration can be difficult to foster. In response, some scholars highlight the importance of parent engagement training opportunities for teacher candidates as well as teachers in service (Dotger \& Bennett, 2010; Henderson et al., 2007). Training holds promise for teachers and support staff to build their skills around learning about the families and communities surrounding the school, as well as developing strategies for including families in educational issues (Henderson \& Mapp, 2002).

\section{Leadership For Parent Engagement}

Educational leaders play an important role in training and facilitating the development of strategies for promoting family participation in education (Epstein et al., 2007). The principals' leadership is an essential element in the development of strong partnership programs (Epstein, 2001), for it serves to shape and influence teachers' activities and goals (Donaldson, 2006; Leonard, 1999) and makes parent engagement possible. District-level commitment to home-school-community collaboration also assists school personnel in developing parent engagement initiatives by providing material and

ISSN 2325-6389 
economic resources or by assisting with the development and management of parent engagement initiatives (Epstein et al., 2007; Sanders, 2007).

Distributed leadership is one strategy that has the potential to facilitate principals' and teachers' efforts to promote family participation in education. As Spillane and Diamond (2007) note, there are two components to the concept of distributed leadership. The element of distribution acknowledges that leading and managing an organization such as a district or a school is the purview of many individuals who may or may not be in formal leadership positions (Blanchard, 1996; Kotter, 1995; Spillane \& Diamond, 2007). More than this, a distributed perspective of leadership and management practice takes into account the interdependence and interaction of individuals (both leaders and followers) and the environment (the circumstances or situation). "This distributed view of leadership shifts focus from school principals and other formal and informal leaders to the web of leaders, followers, and their situation that give form to leadership practice" (Spillane \& Diamond, 2007, p. 7).

Similarly, Lambert (2003) observes that participatory or shared leadership is most readily fostered in a school or district environment where "opportunities for skillful participation top the list of priorities" (p. 425), thus enabling an avenue for teacher leadership (Katzenmeyer \& Moller, 2001). Such a culture is fundamental to the development of leadership identities and actions from school community members, according to Lambert (2003). At the school level, leadership support may include legitimizing teachers' leadership roles, verbally reaffirming their leadership activities (Birky, Shelton, \& Headley, 2006), coaching, and feedback (Buckner \& McDowelle, 2000; Kahrs, 1996). The formal leaders "share power, encourage teacher leadership, and set a tone that validates teachers' views and expertise" (Murphy, 2005; Stone, Horejas \& Lomas, 1997, p. 8). While occupying different leadership roles, then, both principals' and teachers' leadership are essential for the creation of the school-level conditions necessary for school-community collaboration development. That said, a distributed perspective of leadership does not preclude parents' leadership in collaborative activities. Indeed, this model allows for parent engagement and families' negotiation of ways in which they participate in education. Yet, a tension exists between the operationalization of a distributed perspective and the existing structures in the education system that has the potential to impact possibilities for parent engagement.

\section{Leadership in Managed Systems and Living Systems}

Leadership for parent engagement takes place within a context. The broader educational environment is hierarchically arranged (Anyon, 2005) in Western societies, including provinces such as Ontario (Curtis, 1988; Murphy, 1997). As such, it is necessary to look at the cultural issues at play in the education system with reference to its structures. Elements of organizational culture include observed patterns of behavior when people engage with one another, group norms, espoused values, a formal philosophy for the organization, members' specific skills, their habits of thinking or the mental models they use, and shared meanings (Schein, 1995). The patterns of beliefs, values, social and political relations, as well as expectations that guide behavior and practices (Gilley, 2000; Steiner, 2002) can result in "rules, policies, procedures, and 
processes that define and contain organizational activity" (Mitchell \& Sackney, 2011, p. 21). Mitchell and Sackney point out that these elements define choice and shape behavior for members of the culture. Therefore, the actions of the district- and school-level leaders, the educators, and the families associated with the culture are all influenced by its characteristics (cf. Datnow et al., 2002).

Consistent with a hierarchical model, most schools (and their districts) are managed systems (Starratt, 1996, Mitchell \& Sackney, 2011) and have been since the industrial era, when they were set up to reflect the factory model prevalent in the industrial and technical economy of the 18- and 1900s (Tyack, 1974). This model was designed to educate large groups of students in urban centers with an emphasis on predictability, efficiency, and compliance (Mitchell \& Sackney, 2011; Tyack, 1974).

Vertical structures, top-down decision-making, and rule- and role-based activity became the operating principles in social institutions, and the language of rules, standards, expectations, outcomes, policies, procedures, compliance, order, and control became the common lexicon and root metaphors that scripted people's lives. (Mitchell \& Sackney, 2011 p. 23)

These are the features that can be seen to shape the current education system. As a result, the decision-making typically resides within formal leaders, such as district-level administrators and school principals. This underlying premise is reflected in the family involvement literature, which calls for school personnel to reach out to parents in order to promote involvement (see Davies, 2002; Epstein, 1995, 2001; Sheldon, 2005). It also limits parents' ability to negotiate space and their agency, or actions, within that space (Barton et al., 2004).

In contrast to the managed system, a living systems model is an alternative approach to conceptualizing education (see Sackney \& Mitchell, 2008). A living system is self-generating and changes in response to the feedback it receives from the broader environment without modifying its purpose (Capra, 2002, 2007). In this perspective, all aspects of our universe are interconnected, and they influence, and are influenced, by each other (Capra, 2002; Mitchell \& Sackney, 2011). Social networks, such as education systems, are based on relationships among people and their environments, and this influences the way people and their environment interact with one another (Capra, 2007). There is a purpose for the network's existence and functioning. Cultural meaning, related to "ideas, values, goals, conflicts and relationships of power" (Capra, 2007, p. 478), for example, is attached to these interactive processes. The interdependence of all elements in the living system network focuses on the relationships and activities that develop among and between people and their environments (Capra, 2002), such that feedback from these processes can result in the introduction of new people and environmental elements and the emergence of new relationships within the network (Capra, 2007). This is a particularly useful perspective when considering school-family partnerships or family engagement in education (Hands, 2005). It highlights the necessity of viewing families as integral components of the education system's social network, of taking into account the interrelationships among parents, district and school personnel, curriculum and other manifestations of education, and of considering the role of environmental influences. A living system model also accommodates a distributed leadership perspective that enables

ISSN 2325-6389 
families to negotiate their place in the education system and to take on leadership roles in the network.

The difficulty arises when a living system conducive to meaningful engagement, in which parents are able to negotiate a space for themselves and their participation in education, is situated in a managed system, such as our current education system. This research highlights this tension and illustrates the limitations to family engagement as a result. In the section that follows, I outline the methods used for data collection and analysis and describe the school district on which this study is based.

\section{Methodology}

In order to reveal the perspectives of those involved with or impacted by the parent engagement initiatives, this investigation used a qualitative case study research design. Case study methodology was chosen to allow the examination of the process and consequences of parent engagement initiatives in the real-life context in which they are occurring (Yin, 1994).

Data Collection. All of the parent engagement initiatives in the study were funded by the Ontario Ministry of Education, for their potential to involve families in learning and teaching with the goal to promote student achievement and wellbeing. In total, eight initiatives were involved in the research. In order to examine the nature of district support for parent engagement and issues of inclusion, the main selection criteria for this paper were: evidence of parent engagement as part of the district's responsibilities and a culturally and economically diverse district. Of the eight initiatives, only one district had a strategic plan that included parent and community involvement and employed a superintendent with responsibility for promoting parent engagement and developing initiatives. This district also had a community resource facilitator team to work with school personnel in collaborating with citizens and community organizations on educational issues. District I was unique, because their parent engagement initiative was actually five different initiatives that targeted specific issues that together were intended to enhance inclusion. To that end, the superintendent involved a number of educators, families, and community members. The initiatives were tailored to schools' and families' needs based on the district's demographics.

The case study on which this paper is based focused on the strategies in one district characterized by culturally and economically diverse school communities. District I was located in a region on the northern border of a large, urban center. The region was culturally diverse, with upwards of 90 languages spoken by residents. Between $12.2 \%$ and $57.9 \%$ of the population was foreign-born, with between $7.6 \%$ and $57.0 \%$ of the residents' first language other than the official languages of English or French (Statistics Canada, 2012). Between $2.3 \%$ and $38.5 \%$ of the residents most often spoke a language other than English or French at home (Statistics Canada, 2012). The region's residents also had a range of socioeconomic status. The population 15 years of age and older with a total income of less than $\$ 27,815$ ranged from $43.6 \%$ to $54 \%$, with $7.4 \%$ to $13.2 \%$ classified as low income ${ }^{3}$. In contrast, the $8.3 \%$ to $20.6 \%$ highest earning residents had a total income of $\$ 80,420$ and greater (Statistics Canada, 2012).

Twenty-seven individual and twenty focus group interviews that were semistructured, open-ended and approximately 45 minutes in length were conducted for the 
study. District I's eight interviews included project coordinators (two district-level support staff, one superintendent, one principal), school board personnel (two districtlevel support staff, one board community resource facilitator team member, one curriculum administrator), parents (eight), and community partners (one local Catholic Community Services representative, one Ontario Works representative). The interviews were digitally audio recorded and transcribed and detailed notes were taken during the interviews. Transcriptions of the interviews were made available to participants as a member check (Creswell, 2012), and the participants had the opportunity modify or edit their comments. Observations were made and field notes were taken during site visits. Documents and other artifacts from the initiatives, such as brochures, radio and printed advertisements, evaluation forms, and PEO final reports from the project coordinators were collected during and after site visits and from the PEO. Additionally, school board and Statistics Canada websites were accessed for contextual information. Demographic information was collected on the communities and the school districts, as well as information on the parent engagement initiatives, activities, and resources for families. Multiple sources of data were sought in order to establish construct validity through triangulation (Merriam, 1998; Rothe, 2000).

Data Analysis. Upon reviewing audiorecordings, transcriptions, and interview notes, archival data and observations, the collected data were coded for text that reflected the existing literature and research questions (Creswell, 2012; Merriam, 1998). Also, all of the spontaneous categories were coded (Creswell, 2012). The constant comparative method of analysis was used; the data obtained from each participant were continuously examined, and incidents were compared across the data (Bogdan \& Biklen, 1982; Creswell, 2012; Rothe, 2000). In doing so, new categories and themes were developed and existing ones were evaluated and modified (Merriam, 1998).

\section{Findings and Discussion}

Several themes emerged during the data analysis that highlighted shared leadership strategies to promote capacity among educators, school council members, and also parents, who typically experience difficulty becoming engaged in their children's education. In the following section, I outline the approaches used by the superintendent to promote and to enhance the initiatives' accessibility.

\section{Supporting Inclusive Cultures at the School Level Through District Leadership \\ When District I's superintendent, Roberta Mack, took responsibility for parent engagement initiatives, she noted,}

If I've got this job, why don't I have a team assigned at the schools and district to help me with developing parent engagement? I knew I couldn't do it alone. What I found was I needed to get people on board who had an interest in engaging families. The membership of the group changed as I worked with different people on each initiative. (personal communication, July 10, 2008)

Roberta recruited principals, district consultants and members of the district's community resource facilitator team who were supportive of parent engagement to work with her; however, she and her leadership team realized they needed to build capacity and interest at the school level. For initiatives to be implemented and sustained at the school level, 
there needed to be support and a shared understanding of family-school-community partnerships in the schools (Hands, 2005; Sanders, 1999).

In order to promote home-school collaboration, issues of organizational culture need to be considered. As the literature and some of the interview participants (GIVE program and engagement audit) in this research noted, a welcoming school environment is essential (Sanders \& Harvey, 2002). This requires buy-in from all school community members. In order to foster conditions conducive to parent engagement initiative development, the superintendent worked with her leadership team to provide teachers with an understanding of parent engagement and its benefits, as well as to create opportunities for school personnel and families to get to know one another in a setting conducive to collaboration.

Parent engagement handbook for new teachers. To encourage educators to take on a leadership role to develop and implement parent engagement initiatives in their classrooms and schools, Roberta supported the creation of a handbook on parent engagement for new teachers. It was to be distributed to the teachers during a districtwide workshop on parent engagement as part of the New Teacher Induction Program. The district's curriculum consultant and project coordinator, Sandra, stated,

The big goal for me is to make new teachers understand what a gift it is to have parents who are engaged, how it can absolutely change your relationship with the children, with the parents and for student achievement. The kids will do better.... What this is going to do is help our teachers be better teachers, to reach the children more effectively by understanding where they're coming from and the assets that they have in their home and in their community. (personal communication, July, 21, 2008)

Strategies such as these were a start toward providing learning opportunities around parent engagement for school personnel. Mitchell and Sackney (2011) note that teachers (and others) gravitate to initiatives that address their interests and urgent concerns. In this case, the training for new teachers was optional. It was one of an array of workshops on various topics the district offered throughout the year to new teachers. As such, only those teachers with an interest in learning more about working with families were likely to take the workshop. Opportunities for all school personnel to develop their understanding of family and community engagement and its relevance to education and student achievement would be helpful toward developing comprehensive parent engagement programs (cf. Epstein et al., 2007; Sanders, 2007). Toward that end, teacher buy-in is needed for any educational reform initiatives' success (Datnow et al., 2002). The superintendent and curriculum consultant developed the workshop and handbook content without consulting with the principals and teachers around their learning needs. This approach is reflective of the managed system (Mitchell \& Sackney, 2011) and may influence buy-in and the district's educators' general interest in the handbook.

The Families and Schools Together (FAST) program. Recognizing the cultural diversity and the range of income levels across the district, the superintendent and her leadership team looked for initiatives that would provide support to newcomers to Canada and those experiencing financial challenges, as well as encourage relationshipbuilding among families and school personnel. The FAST program was "designed to 
reach high risk, low income, highly stressed families, and newcomers to the community. It brings people into the school as a hub, ... building community within their own school environment," according to Wendy Swanson, a counselor with the local Family Services unit and FAST program coordinator for District I (personal communication, July 16, 2008). Teams of school personnel and community members, including a Family Services (mental health) counselor, one or two teachers, the principal, a child and youth worker, a parent, and community partners (e.g., a police officer, a city Parks and Recreation or YMCA worker) delivered the program at the school sites. Wendy observed that "parents can be intimidated to seek out resources in the community on their own.... They can have a strained relationship with schools because of the behavior issues of students." The FAST program had a focus on strengthening the family unit, with family activities such as art therapy, cooperative games, and explorations of others' perspectives and feelings, as well as parenting training and information on community resources led by social services representatives, and group meals for the participating families, educators, and social services representatives during the sessions. It was a prescriptive, service delivery model with decisions around implementation made by formal leaders and established roles and activities, which was reflective of a managed system (cf. Mitchell \& Sackney, 2011).

The program was externally developed ${ }^{4}$, and as such, it did not take into account District I's context, which potentially affected buy-in (cf. Datnow et al., 2002).

Regardless, the program was implemented at schools that requested it. After the program, Wendy noted that there "[is a] big difference with how connected families are with their children... Parents are not afraid to come into the school. They see [school personnel] in a different light, interacting socially with their children." The parents interviewed in this study were in agreement. All were newcomers to the country. One mother recalled that parents learned "how to provide an education to kids. [We] learn from the teachers.... I volunteer in school. I tie children's skates, and work in the class to help the teacher. I wasn't volunteering before the FAST program." Another parent observed that the program was particularly useful for families who were newcomers to the country because the program allowed for the children to get to know other children and helped the parents with schooling and socializing. With program activities predetermined in the absence of family input and with no opportunity for parents to negotiate the nature of their participation, the FAST program could not be considered parent engagement (cf. Auerbach, 2011; Barton et al., 2004; Pushor, 2007). That said, it was a way for school personnel and parents to socialize and to create a school community culture that was conducive to parent engagement. This program could therefore be seen as a springboard for parent engagement initiatives and leadership in the future.

\section{District Support and Sharing Leadership With Principals and Parents at the School Level}

Several of District I's initiatives had the potential to engage parents in their children's education and highlighted the superintendent's actions to share leadership among her team members and parents to build capacity for parent engagement across the district. Several of the district's principals were interested in enhancing their parent engagement, so Roberta invited them to be on a parent engagement committee, along 
with a district curriculum consultant and members of the district's Community Resource Facilitator Team. She arranged for the team to accompany her to a workshop on parent engagement organized by the National Network of Partnership Schools in Baltimore. Roberta then initiated three local strategies to dispel the myths around engagement and to develop programs tailored to families' and school personnel's needs. In doing so, she shared leadership with district-level personnel, community members, and parents for their development.

In order to develop comprehensive parent engagement programs in schools with a range of activities that meet the families' and schools' needs, it is necessary to gather information (Epstein, 1995). Two of the initiatives focused on gathering information to shape parent engagement activities at the school level. Roberta noted the importance of data collection, when she stated that

Teachers have a perception of what a good parent looks like and does.... What I really want is for all of us to stop assuming and know first. Get to know first, then make your plans and do your outreach, or whatever, or your joint planning. Base it on fact, not on perceptions. (personal communication, July 21, 2008) Similarly, Jasmeena, a first-year principal with 21 years of experience with the board, observed, "Parents with time and cultural currency are those that are perceived as engaged. If we use this frame of reference, then lots of parents aren't considered engaged. This isn't true, though" (personal communication, June 24, 2008). In addition to assumptions regarding how parents should be involved and what capacity for involvement they have (see Quiocho \& Daoud, 2005), other research has similarly found that some teachers who are unfamiliar with the language, economic status, and cultural traditions of their students assume that students' families and members of the surrounding community are not interested or do not care to be involved in their children's education if they fail to attend events planned by school personnel (Hubbard \& Hands, 2011). This speaks to the importance of gathering information to dispel assumptions before creating opportunities for collaborative activities involving families.

A principal's development of a parent engagement audit. Roberta intended for the initiatives to meet the needs of all families. As a first step, she and her team developed a school parent engagement audit to identify what parent engagement activities were taking place in schools and areas in the programming and resources that could benefit from parent engagement. This involved consulting families directly when determining what they needed and the types of parent engagement activities that would be appropriate (Henderson et al., 2007). Jasmeena was a team member with a particular interest in actively playing a role. According to her, there needs to be "alignment between school and home. This is understood by educators, but how to achieve this isn't" (personal communication, June 24, 2008). With the support of Roberta, Jasmeena conducted walk-throughs of her school with parent groups, and she developed a parent engagement audit, based on Epstein's (1995) six types of involvement, in collaboration with the parents that could be used by educators and school council members at other schools. The audit was a "touchstone, a reflective tool," according to Jasmeena, and included sample activities and opportunities to evaluate their presence at the school, as well as considerations for future practice. Jasmeena noted that school administrators could adjust the audit to suit their contexts and use it on walk-throughs with teachers and

ISSN 2325-6389 
parents to make clear what school practices needed examination, why, and perhaps even how to make any needed changes in parent engagement practices. It could be used as a strategy to make the existing practices clear and to start a collaborative conversation among educators and families.

The superintendent encouraged the audit's development by assembling an advisory board, including trustees, the board's director of education, and administrators to provide guidance and feedback. This kind of coaching and feedback, found to be essential in fostering leadership broadly in schools (Buckner \& McDowelle, 2000; Kahrs, 1996), also seems to promote shared leadership at the district level. The superintendent validated Jasmeena's work on the audit by reviewing her efforts and providing verbal encouragement of her leadership activities, similar to the research on teacher leadership (see Birky et al., 2006; Murphy, 2005; York-Barr \& Duke, 2004). The superintendent also created opportunities for capacity-building by providing the funding and time needed for Jasmeena to develop her knowledge on parent engagement and the opportunity to share her learning in the form of an audit tool for general use among her colleagues (cf. Epstein et al., 2007; Sanders, 2007). These activities are consistent with Lambert's (2003) notion of a leadership identity developed through a skill-building organizational culture.

Leadership identity regarding parent engagement development did not necessarily transfer to other school leaders. At the time of the research, principals across the district had adopted the audit on a voluntary basis. The audit was not widely used as a tool for building capacity around parent engagement. Further, parents' and teachers' inclusion in its use and interpretation at their schools was optional, in keeping with a managed system. While parents at Jasmeena's school were able to negotiate spaces to engage in their children's education, this was not necessarily the case for parents at other schools. Also, the teachers' limited levels of involvement highlight the necessity for teacher training (Henderson \& Mapp, 2002) beyond optional professional development for new teachers.

The superintendent's and principals' development of school council training. Roberta provided opportunities for leadership to be distributed beyond her committee of administrators, as well. She coordinated parent engagement training for school councils in her family of schools as a way to increase the number of ways in which parents were engaged, as well as to increase the number of parents engaged (cf. Sanders, 2007). As Roberta observed, the school council members could

reach into the homes. [I] remind the council that they are representing all parents and they are responsible for getting access to all parents. They can do a better job than schools... [to] drum up business... and to get other parents involved. They know what's reasonable for the community. (personal communication, August 14, 2008)

Together with her team of administrators, they "thought about what it might look like for school councils to be involved in parent engagement," (personal communication, August $14,2008)$ and they created a training workshop for the council members. Members of the school councils in the family of schools participated in the workshop, where they were given an overview of Epstein's (1995) types of family involvement in education and guidance on collecting demographic statistics from the district and national demographic databases, as well as interpreting the families' and communities' needs from the data. 
Each school council then worked on one aspect of its school's plan for continuous improvement with a focus on student achievement, guided by a staff member on the council, the community resource facilitators at the board, and a principal from Roberta's team of administrators, to ensure that the events planned were "doable" for the school. Planning for parent engagement could include school council members going door-todoor, corresponding with families electronically, conducting parent surveys, and collecting demographic data on the communities surrounding the schools. Here the superintendent and her team built capacity among groups of parents with the intent that they would initiate parent engagement initiatives in their locales. Again, this structure reflects a shared leadership approach, in which principals guide parent groups, and parent groups take the lead in deciding the nature of the parent engagement and the strategies to achieve it, with the support of the superintendent (cf. Lambert, 2003).

The inclusion of parent training broadens concepts of distributed or shared leadership, for school-family collaboration can extend educational leadership opportunities to parents (Epstein et al., 2007; Sanders, 2007), as it did in this case. The district leadership team was looking to establish new ways for constituents to interact with one another and with the various educational environments across the district, which is reflective of a living systems model (see Capra, 2007). That said, the leadership team determined the parameters of family engagement and leadership opportunities for parents. They outlined the expectations, the training content (or learning opportunities), and the procedures and strategies for parent engagement, which is consistent with education in managed systems (see Mitchell \& Sackney, 2011). Similarly, the school administrators, not parents, determined their school's goals for continuous improvement in keeping with the district's strategic plan, and all activities were to conform to the goals. Here, we do not see opportunities for parent engagement, in which families negotiate their space and participation within the environment (cf. Barton et al., 2004; Pushor, 2007). Rather, this strategy is reflective of parent involvement (Pushor, 2007).

A team of educators, community members and parents create the Get Involved: Volunteer in Education (GIVE) program. The superintendent and her team of district-level leaders created one parent training program in particular to promote parent engagement widely across the culturally and economically diverse district. Specifically, a District I Community Resources Facilitator Team member coordinated the program and the development team. The GIVE program was designed to introduce families to the education system in Ontario and the services available to them in the community, as well as to provide opportunities for parents to gain skills and work experience. As a result, the program included representatives from social services, such as Ontario Works and Community and Health Services, in the planning and delivery of the programs, similar to the FAST program. Workshop session topics created and presented by the organizers included nutrition, resiliency, stress and self care, effective communication, and cultural competency. Also, there were opportunities for participants to socialize with one another and with social services representatives. Additionally, the program also included training on supervising children, school board policy, the school board structure, bullying prevention, child behavior, pedagogical strategies, and problem solving and conflict resolution. Consequently, the parents were trained to participate in 
activities directly related to teaching and learning at their children's schools. As one parent, who was a newcomer to Canada, stated,

They have three hours of training for us first, and they give us more information.... You have to know what you should do,... how to deal with children. And after the training, you will feel comfortable [to] volunteer.... After that, you volunteer two days a week in the schools. It's like you're teaching. You have some responsibilities.... I help [with] reading, I help Grade 1, Grade 2.... CITATION?

The superintendent turned over the leadership for developing and implementing the GIVE program to a district employee. Roberta participated in meetings and reviewed the progress with the project coordinator. In this way, she affirmed the group's work, consistent with the leadership research of scholars such as Birky and colleagues (2006) and Murphy (2005). Here, the interdependence of individuals and the environment is evident in the group's programming, and leadership practice can be best depicted as a web of leaders, followers, and their social contexts (cf. Spillane \& Diamond, 2007).

Practically, the program demonstrated multiple interdependencies that were essential to successful program delivery. Money from the district was not available to the program. There was no board space for the workshop sessions, and community partners provided centrally located meeting rooms for the sessions. Also, session facilitators and community representatives participated free of charge or in-kind. Epstein and her colleagues (2007) caution that adequate financial support is essential to assist district leaders in supporting schools' partnership program improvement. Regardless of financial constraints, the GIVE program extended the capacity for all to be engaged. Opportunities for families to build their skills expanded their options for participating in their children's education. Further, the GIVE program gave families opportunities to provide feedback after the workshops or activities in which they were involved. Their opinions and suggestions were considered and implemented where possible in future events. This illustrates the opportunities families had to influence education through shared leadership; however, the program also served to socialize the families to the educational culture - "the way we do things around here" (Burke, 1992, p. 130)—so they could participate in ways delineated by leaders at the district and school levels. With a focus on educational policies and school board structure, as well as volunteering opportunities currently established and supported by the educational leaders and school personnel, a managed system is evident (Mitchell \& Sackney, 2011), with limited opportunities for parents to create their unique contributions (cf. Barton et al., 2004) that would provide evidence of a living system (cf. Capra, 2007). There was no evidence that families were encouraged to prepare for the process of negotiating their participation in their children's education. Rather, the structure of the GIVE program promoted acceptance of and conformity to the existing educational system and the structures in place within the individual schools.

\section{Implications}

This paper provides a picture of some of the strategies used in an Ontario school district to ensure that all families had opportunities to become engaged in their children's education. Because of the sample size and the qualitative nature of the investigation, the

ISSN 2325-6389 
findings of this research may not be broadly applicable beyond the district in the study (Merriam, 1998). Initiatives undertaken by districts, schools, community agencies, or any other action group are selected based on the districts' or schools' needs and those of the parents (Epstein, 1995, 2001). That said, the strategies employed by the superintendent and her leadership team in this study to develop a comprehensive parent engagement program is of interest to those who may seek to do the same within their social context. What follows here is a discussion of the study's implications for policy, practice, and future research.

\section{Building Capacity, and Enhancing Inclusivity and Support for Parent Engagement}

In order to promote student achievement and wellbeing and to reduce achievement gaps, it is essential to engage all families in their children's education (Henderson et al., 2007; Quezada, 2003; Pushor, 2007; Pushor \& Ruitenberg, 2005). There are implications for provincial- or state- and district-level policymakers in this area. District-level policies and support to engage all families in education are needed in the form of money, as well as training and time during the workday for educators to develop collaborative relations (Sanders, 1999).

Financial support is needed for initiatives such as the ones in this paper. Roberta facilitated the leadership of others to develop the GIVE and FAST programs, but they not only required time to coordinate multiple community services and a training program, but also funding (cf. Epstein et al., 2007; Sanders, 2007). Support from provincial- or statelevel education departments to mitigate the cost of providing services, as well as administrative and production costs, may enable more schools or districts to create a program with a wider range to reach more families and community members where they might not otherwise be able to do so. It might also be possible for provincial ministries or education departments, for example, to provide guidance to districts interested in writing proposals for grants from community organizations to support their initiatives.

Some scholars note that school personnel need to initiate relationships with families (Epstein, 1995, 2001; Henderson et al., 2007; Sheldon, 2005). This points to the hierarchical nature of the education system as a managed system and also to the crucial roles that professional development and opportunity to create parent engagement opportunities can play. In this paper, time and some limited training were available for parent engagement initiatives. District I's administration placed importance on parent engagement by including it as part of the superintendent's responsibilities. As such, time was available to her for school-family partnership development. In fulfilling her role, the superintendent provided time during the day and organized consulting groups for the parent engagement audit creator, as well as for her administrative team's development of the school council training. In order to promote the leadership of parents on the school council, the superintendent and her team of administrators provided training at the district level to assist them in creating engagement opportunities for their school communities. The district leaders also offered training for new teachers to help create a school and classroom culture that was supportive of parent engagement as well as new initiatives.

While there was some training for educators, there were limitations. The training was optional and available only for new teachers and those acting as school council representatives. It is necessary to provide educational and professional development opportunities for pre- and in- service educators (Henderson \& Mapp, 2002). Training 
sets the stage for creating a school environment that welcomes parent engagement (Epstein et al., 2007; Dotger \& Bennett, 2010). In their meta-analysis of parent engagement initiatives, Henderson and Mapp noted when training was provided to teachers and other school staff, the level and nature of contact between themselves and families changed in ways that improved families' perceptions of the school and their relationships with teachers. It also affected how families were involved in their children's schooling (Henderson \& Mapp, 2002). Toward that end, the teacher training can provide compelling evidence of the benefits of family involvement in education, and opportunities for educators to change their practices to include more family participation. Yet as Henderson and Mapp observe, other school staff need training as well as teachers. Administrators, teachers, and support staff are all candidates, since all of these school community members have opportunities to interact with parents and citizens of the broader community. If they are not included in these efforts, engaging families in educational matters will likely remain within the scope of those educators who have an existing interest in doing so. Provincial and state education departments, universities, professional organizations including unions, the districts, and the schools can all take a role in improving the quality and quantity of parent engagement possibilities by providing the human, material, and financial resources needed to develop professional learning opportunities around parent engagement.

\section{Authentic or Contrived Engagement? The Limitations of a Living System's Growth within a Managed System}

As is illustrated in this paper, educators at the board and school levels initiate parent engagement opportunities (Epstein, 2001; Epstein et al., 2007; Sheldon, 2005). At the very least, they shaped the ways in which families were involved in education in this study. This feature is characteristic of a managed system, in which top-down authority and decision-making prevails in an environment where policies, rules, and procedures "direct and contain school processes" (Mitchell \& Sackney, 2011, p. 26). Yet as Barton and colleagues (2004) note,

Actions that engage are both about how parents activate the resources available to them in a given space in order to author a place of their own in schools and about how they use or express that place to position themselves differently so that they can influence life in schools. (p. 8)

This is characteristic of a living system, in which members of school communities learn and engage with one another "in ways and timeframes that are appropriate for their styles, meaningful for their purposes, and respectful of their identities" (Mitchell \& Sackney, 2011, p. 30). While school personnel's understanding of the role of parents in education is reflected in the environment and the opportunities for family engagement (Barton et al., 2004), the authorship of parents is highlighted.

In this study, the school council members had some latitude to develop their own parent engagement initiatives; however, they did not create new opportunities to become engaged outside of the schools' prescribed foci, nor did any other parents. The extent of shared leadership was determined by the district-level leadership within a managed system, and parents could negotiate their space and agency within a limited choice presented to them by educational leaders. Similarly, parents involved in the GIVE 
program were socialized into the existing system and encouraged to volunteer in schooland district-approved ways. This may be particularly problematic in school communities with diverse families. Scholars note that educators' life experiences may not match those of the families (Metz, 1986, 1990) and consequently, families' circumstances may not be well understood (Leithwood \& Jantzi, 2006). Although gathering information is part of the process, and the superintendent and her leadership team made efforts to find out about the community before designing the initiatives, more could be done in this area beyond gathering information. For example, home visits are a good way for educators to gain an appreciation of the multiple contexts that are influencing and are influenced by families (Hiatt-Michael, 2010; Pushor, 2011). These opportunities for parents and teachers to exchange information can contextualize parents' experiences and can be used to interrupt dominant narratives or assumptions among teachers regarding what, how, when, and why parents are involved in their children's education (Quiocho \& Daoud, 2005; Pushor, 2011; Pushor \& Ruitenberg, 2005).

Authentic partnerships, involving a sharing of information and collaboration in developing initiatives (Auerbach, 2011), were not evident. Parents were not included in determining school and district goals or the breadth and depth of engagement opportunities for the parents. As a result, families' expectations or desires for particular ways of being involved may or may not have been reflected in the engagement opportunities. In turn, this runs the risk of parents' lack of engagement, or disengagement, in their children's schooling. How might parents author new ways to become engaged in their children's education so "they can influence life in schools in nontraditional and informal ways" (Barton et al., 2004, p. 11)? More research needs to be done on the ways in which diverse parents negotiate their engagement in education beyond that which is prescribed by the school.

\section{Conclusions}

This study brings together some informative ideas around district-level leadership for parent engagement. The initiatives in this study hold promise for providing opportunities for educators' and parents' empowerment and leadership; nevertheless, they have limits. They are reflective of a living system; however, they are being implemented within a managed system. Moreover, parent engagement will likely be supported only by those educators who have an interest in collaborating with families, unless educators have compelling reasons to change their practices to include parents (cf. Capra, 2002; Mitchell \& Sackney, 2011). With the balance of power residing in the school district and schools, it also may be difficult for parents to be involved in capacities of their choice. There needs to be an understanding and support of initiatives in Ontario and beyond that provide parents with the skills necessary to advocate for education that meets the needs of their families as well as those of others (cf. Barton et al., 2004; Harvard Family Research Project, 2002). Opportunities for families to be involved in education at the school and district levels in ways that are endorsed by the school and the district, but also in ways that originate within the parent community, are needed. When that occurs, all families will have the capacity to be authentically engaged as partners in their children's education.

ISSN 2325-6389 


\section{Notes}

1. All names used in this paper are pseudonyms to preserve confidentiality.

2. Both the parent engagement initiatives and the research on them were funded by the Ontario Ministry of Education's Parent Engagement Office.

3. The after-tax low income measure (LIM) in 2010 was $\$ 19,460$ for a one-person household, multiplied by the square root of the household size for larger households (Statistics Canada, 2012).

4. The FAST program was developed by Dr. Lynn McDonald in Madison, Wisconsin in 1988. For more information, see the Wisconsin Center for Education Research website at www.wcer.wisc.edu/projects.php?project num=64.

\section{References}

Anyon, J. (2005). Radical possibilities: Public policy, urban education, and a new social movement. New York, NY: Routledge.

Auerbach, S. (2011). Introduction: Why leadership for partnerships? In S. Auerbach (Ed.), School leadership for authentic family and community partnerships (pp. 39). New York: Routledge.

Barton, A. C., Drake, C., Perez, J. G., St. Louis, K., \& George, M. (2004). Ecologies of parental engagement in urban education. Educational Researcher, 33(4), 3-12.

Birky, V. D., Shelton, M., \& Headley, S. (2006). An administrator's challenge: Encouraging teachers to be leaders. NASSP Bulletin, 90(2), 87-101. [Electronic version.] 
Somewhere between a Possibility and a Pipe Dream

Blanchard, K. (1996). Turning the organizational pyramid upside down. In F. Hesselbein, M. Goldsmith, \& R. Beckhard (Eds.), The leader of the future (pp. 81-86).

Bogdan, R. C., \& Biklen, S. K. (1982). Qualitative research for education: An introduction to theory and methods. Boston, MA: Allyn \& Bacon.

Buckner, K. G., \& McDowelle, J. O. (2000). Developing teacher leaders: Providing encouragement, opportunities, and support. NASSP Bulletin, 84(616), 35-41.

Burke, W. W. (1992). Organizational development: A process of learning and changing. Reading, MA: Addison-Wesley.

Capra, F. (2002). The hidden connections: Integrating the biological, cognitive, and social dimensions of life into a science of sustainability. New York, NY: Doubleday.

Capra, F. (2007). Complexity and life. Systems Research and Behavioral Science, 24, 475-479.

Cooper, C. W. (2009). Parent involvement, African American mothers, and the politics of educational care. Equity \& Excellence in Education, 42(4), 379-394.

Creswell, J. W. (2012). Educational research: Planning, conducting, and evaluating quantitative and qualitative research $\left(4^{\text {th }}\right.$ ed.). Boston, MA: Pearson.

Curtis, B. (1988). Patterns of resistance to public education: England, Ireland, and Canada West, 1830-1890. Comparative Education Review, 32(3), 318-333.

Davies, D. (2002). The $10^{\text {th }}$ school revisited: Are school/family/community partnerships on the reform agenda now? Phi Delta Kappan, 83(5), 388-392.

Donaldson, G. A., Jr. (2006). Cultivating leadership in schools: Connecting people, purpose, and practice ( $2^{\text {nd }}$ ed.). New York, NY: Teachers College.

Dotger, B., \& Bennett, J. (2010). Educating teachers and school leaders for school-family partnerships. In D. B. Hiatt-Michael (Ed.), Promising practices to support family involvement in schools (pp. 129-149). Charlotte, NC: Information Age.

Epstein, J. L. (1995). School/family/community partnerships: Caring for the children we share. Phi Delta Kappan, 76(9), 701-712.

Epstein, J. L. (2001). School, family, community partnerships: Preparing educators and improving schools. Boulder, CO: Westview Press.

Epstein, J. L., Gallindo, C., Sheldon, S. B., \& Williams, K. J. (2007, April). Levels of leadership: Effects of district leadership on the quality of school programs of

ISSN 2325-6389 
family and community involvement. Paper presented at the annual meeting of the American Educational Research Association, Chicago, IL.

Gilley, J. (2000). Understanding and building capacity for change: A key to school transformation. International Journal of Educational Reform, 9(2), 109-119.

Goldring, E. B. (1993). Principals, parents, and administrative superiors. Educational Administration Quarterly, 29, 93-117.

Hands, C. (2005). Patterns of Interdependency: The Development of Partnerships between Schools and Communities. Unpublished doctoral dissertation, University of Toronto, Ontario, Canada.

Hands, C. M. (2009). Architect, advocate, coach and conciliator: The multiple roles of school leaders in the establishment of school-community partnerships and the impact of social context. In K. Anderson (Ed.), The leadership compendium: Emerging scholars in Canadian educational leadership (pp. 193-213). Fredericton, NB: Atlantic Centre for Educational Administration and Leadership.

Harvard Family Research Project. (2002). Concepts and models of family involvement. Retrieved from the world wide web on March 11, 2004 at http://www.gse.harvard.edu/hfrp/projects/fine/resources/case_study/intro.html\#to p.

Henderson, A. T., \& Mapp, K. L. (2002). A new wave of evidence: The impact of school, family, and community connections on student achievement. Austin, TX: Southwest Educational Development Laboratory.

Henderson, A. T., Mapp, K. K., Johnson, V. R., \& Davies, D. (2007). Beyond the bake sale: The essential guide to family-school partnerships. New York, NY: The New Press.

Hiatt-Michael, D. B. (2010). Communication practices that bridge home with school. In D. B. Hiatt-Michael (Ed.), Promising practices to support family involvement in schools (pp. 22-55). Charlotte, NC: Information Age.

Hoover-Dempsey, K. V., Bassler, O. C., \& Brissie, J. S. (1992). Exploration in parentschool relations. Journal of Educational Research, 85, 287-294.

Hubbard, L., \& Hands, C. M. (2011). The role of leadership in forging family-schoolcommunity relationships. In C. M. Hands \& L. Hubbard (Eds.), Including families and communities in urban education (pp. 41-68). Charlotte, NC: Information Age. 
Somewhere between a Possibility and a Pipe Dream

Jeynes, W. H. (2005). A meta-analysis of the relation of parental involvement to urban elementary school student academic achievement. Urban Education, 40(3), 237269.

Kahrs, J. R. (1996). Principals who support teacher leadership. New Directions for School Leadership, 1, 19-40.

Katzenmeyer, M., \& Moller, G. (2001). Awakening the sleeping giant: Helping teachers to develop as leaders ( $2^{\text {nd }}$ ed.). Thousand Oaks, CA: Corwin Press.

Keyes, M. C., \& Gregg, S. (2001). School-community connections: A literature review. Charleston, SC: AEL.

Kotter, J. P. (1995). What leaders really do. In J. T. Wren (Ed.), The leaders companion: Insights on leadership through the ages (pp. 114-123). New York, NY: The Free Press.

Lambert, L. (2003). Leadership redefined: An evocative context for teacher leadership. School Leadership \& Management, 23(4), 421-430. [Electronic version.]

Lareau, A. (1987). Social class differences in family-school relationships: The importance of cultural capital. Sociology of Education, 60, 73-85.

Leithwood, K., \& Jantzi, D. (2006, January). A critical review of the parent engagement literature. Final report. Toronto, Ontario, Canada: Ontario Ministry of Education.

Leonard, P. E. (1999). Examining educational purposes and underlying values orientations in schools. In P.T. Begley (Ed.), Values and educational leadership (pp. 217-235). Albany, NY: SUNY Press.

Merriam, S. B. (1998). Qualitative research and case study applications in education. San Francisco, CA: Jossey-Bass.

Metz, M. H. (1986). Different by design: The context and character of three magnet schools. New York, NY: Routledge and Kegan Paul.

Metz, M. H. (1990). How social class differences shape teachers' work. In M. W. McLaughlin, J. E. Talbert \& N. Bascia (Eds.), The contexts of teaching in secondary schools (pp. 40-107). New York, NY: Teachers College Press.

Ministry of Education. (2005, December). Developing partners in education. Retrieved from the world wide web on March 19, 2009 at http://www.edu.gov.on.ca/eng/document/nr/05.12/developing.pdf.

Mitchell, C., \& Sackney, L. (2011). Sustainable learning communities: From managed systems to living systems. Educational Administration and Foundations Journal, 22(1), 19-38.

ISSN 2325-6389 
Murphy, J. (2005). Connecting teacher leadership and school improvement. Thousand Oaks, CA: Corwin.

Murphy, M. F. (1997). Unmaking and remaking the "one best system": London, Ontario, 1852-1860. History of Education Quarterly, 37(3), 291-310.

Oakes, J., Wells, A. S., Jones, M., \& Datnow, A. (1997). Detracking: The social construction of ability, cultural politics, and resistance to reform. Teachers College Record, 98(3), 482-510.

Olivos, E. M. (2006). The power of parents: A critical perspective of bicultural parent involvement in public schools. New York, NY: Peter Lang.

Parker, D. C., \& Flessa, J. (2011). Poverty and schools in Ontario: How seven elementary schools are working to improve education. Toronto, Ontario, Canada: Elementary Teachers' Federation of Ontario.

Pushor, D. (2007, January). Parent engagement: Creating a shared world. Paper presented at the Ontario Education Research Symposium, Toronto, Ontario, Canada.

Pushor, D. (2011). Keynote speech. West Meadow Elementary School Parent Conference. Podcast retrieved from http://www.youtube.com/watch?v=wplNiORabWA.

Pushor, D., Ruitenberg, C., with co-researchers from Princess Alexandra Community School. (2005, November). Parent engagement and leadership. Research report, project \#134, Saskatoon, SK: Dr. Stirling McDowell Foundation for Research into Teaching.

Quezada, R. (2003). Going for the gold! Field reports on effective home-school community partnership programs. The School Community Journal, 13(2), 137155.

Quiocho, A. M. L., \& Daoud, A. M. (2005). Dispelling myths about Latino parent participation in schools. The Educational Forum, 70, 255-267.

Rothe, J. P. (2000). Undertaking qualitative research. Edmonton, Alberta, Canada: The University of Alberta Press.

Sackney, L., \& Mitchell, C. (2008). Leadership for learning: A Canadian perspective. In J. MacBeath \& Y. C. Cheng (Eds.). Leadership for learning: International perspectives (pp. 123-136). Rotterdam, The Netherlands: Sense.

Sanders, M. G. (1999). Schools' program and progress in the National Network of Partnership Schools. The Journal of Educational Research, 92(4). 
Somewhere between a Possibility and a Pipe Dream

Sanders, M. G. (2007, April). Parents as leaders: A case study of public engagement and educational reform. Paper presented at the annual meeting of the American Educational Research Association, New York, NY.

Sanders, M. G., \& Harvey, A. (2002). Beyond the school walls: A case study of principal leadership for school-community collaboration. Teachers College Record, 104(7), 1345-1368.

Schein, E. H. (1995). Defining organizational culture. In J. T. Wren (Ed.), The leader's companion: Insights on leadership through the ages (pp. 271-281). New York: Free Press.

Schutz, A. (2006). Home is a prison in the global city: The tragic failure of school-based community engagement strategies. Review of Educational Research, 76(4), 691743.

Sheldon, S. B. (2005). Testing a structural equation model of partnership program implementation and parent involvement. The Elementary School Journal, 106(2), 171-187.

Spillane, J. P., \& Diamond, J. B. (2007). Taking a distributed perspective. In J. P. Spillane \& J. B. Diamond (Eds.), Distributed leadership in practice (pp. 1-15). New York: Teachers College Press.

Starratt, R. J. (1996). Transforming educational administration: Meaning, community, excellence. New York: McGraw Hill.

Statistics Canada (2012). National Household Survey 2011 Census, Ottawa, Ontario. Retrieved on May 12, 2014 http://www12.statcan.ca/nhs-enm/2011/as-sa/fogsspg/Pages/CSDSelector.cfm?lang=E\&level=4

Steiner, F. (2002). Human ecology: Following nature's lead. Washington, DC: Island Press.

Stone, M., Horejas, J., \& Lomas, A. (1997). Commonalitites and differences in teacher leadership at the elementary, middle and high school levels. Action in Teacher Education, 19, 49-64. Retrieved October 22, 2007 from http://vnweb.hwwilsonweb.com.myaccess.library.utoronto.ca/hww/results/results 
Catherine Hands

fulltext_maincontentframe.jhtml?url=results_single_ftPES.jhtml\&_DARGS=/h

ww/results/results_single_fulltext.jhtml.

Tyack, D. B. (1974). The one best system: A history of American urban education. Cambridge, MA: Harvard University Press.

Yin, R. K. (1994). Case study research: Design and methods (2nd ed.). Thousand Oaks, CA: Sage Publications.

York-Barr, J., \& Duke, K. (2004). What we know about teacher leadership: Findings from two decades of scholarship. Review of Educational Research, 74(3), 255376. [Electronic version.] 